\title{
EDGE LENGTH EFFECT OF BLUFF BODIES ON FLOW STRUCTURE
}

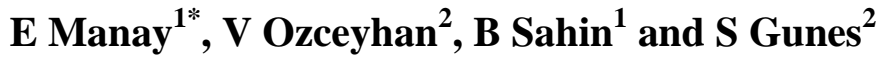 \\ ${ }^{1}$ Faculty of Engineering \& Architecture, Erzurum Technical University, \\ 25040 Erzurum, Turkey \\ *Email: emanay@erzurum.edu.tr \\ Phone : +90-442-6662528; Fax: +90-442-6662535 \\ ${ }^{2}$ Faculty of Engineering, Erciyes University, \\ 38039 Kayseri, Turkey
}

\begin{abstract}
This study investigates the flow structure around two identical triangles placed side by side, through experiment. Its goal is to investigate the effects of the edge length of the bluff bodies on flow structure. The flow characteristics are performed for a Reynolds number range varying from 5.000 to 10.000 under steady state conditions, and the flow was assumed to be two-dimensional. The flow characteristics around the bluff bodies were analyzed using particle image velocimetry (PIV) velocity measurement techniques, with 200 images. Water was used as the working fluid. For each case, velocity distributions along the channel height, velocity vectors and stream lines were presented to get better idea of the change of flow field. The variation in Strouhal number versus Reynolds number is presented. It was concluded for all the gap ratios that the primary recirculation zone and the secondary recirculation zone both occurred because the interaction was not strong. Asymmetrical and unstable flow structure behind the triangles was observed during the experiments. At the point at which the fluid made the first contact with the tips of the bodies, velocity became zero. The most effective parameters were found to be the flow velocity and the back track region. It was concluded that the points on which flow separations occurred moved away by an increasing Reynolds number. Because the vortex fields were symmetrical behind the smooth and the symmetrical elements, the Strouhal number was constant with the changing Reynolds number.
\end{abstract}

Keywords: PIV; Vortex shedding; Triangular body; Strouhal number; Flow formation.

\section{INTRODUCTION}

When explaining why bluff bodies have a wide study and application field, descriptions are often similar and direct researchers to the same information. The bodies, in which stable or unstable sheddings occur in the back regions, are called bluff bodies (Akansu, 2004). Bodies placed in the channel flow, with a large area (perpendicular to the flow field) and causing the flow to leave its surface are called bluff bodies. According to researchers and engineers, fatigue is an important effect specifying the life of systems or materials. Just as the exposure of the system components to the vibration shortens the life of the system, the noise that occurs with the vibration is an important element. The vortex sheddings occur as a result of the fluid encountering the bluff body. As the flow is continuous, periodic sheddings that occur after the separations cause the systems which are integrated with the bodies to fatigue, and the life of the system to decrease. 
Vortex sheddings and formations are of great importance in terms of bluff body fluid dynamics, due to the vibration and the noise (Chiu \& Jang, 2009; Jha \& Sharma, 2013; Lee, 2013; Nuawi, Ismail, Nor, \& Rahman, 2011). The bodies whose back regions are not stable and change continuously due to the bluff bodies may involve oscillations (Akansu, 2004). The bodies with big perpendicular cross sections to the flow field are called bluff bodies providing the fluid is forced to leave the surface as a result of fulfilling the boundary layer theory (Akansu, 2004).

The effects of the different parameters on the flow around the body and at the back track region are investigated in studies of bluff bodies. As reported in the literature, these studies investigate the effects of the different geometries, the change of the dimensions of the bodies and the Reynolds number. In addition to this, the effects of the arrangement types, the number of bodies and the combination of the bodies with different sizes or shapes is also investigated (Akansu, 2004; Ishak, Tahseen, \& Rahman, 2013; Satya Narayana, Ramireddy, \& Venkataramana, 2011; Tahseen, Ishak, \& Rahman, 2012; Vijaya Lakshmi, Subrahmanyam, Dharma Rao, \& Sharma, 2011). Bluff body fluid dynamics are widely reported in the literature due to the complexity of the fluid behavior occurring in the back track region of the bodies. In experimental studies, laser doppler, hot wire anemometer, smoke or particle image velocimetry techniques are used (Choi, Kim, Lee, \& Kim, 2010).

The flow characteristics belonging to the cylinder, square and the 45 degree rotated square inside a channel were investigated by Yuan (2000) for a Reynolds number range of 550-3400. In this study, conducted using the DPIV (digital particle mage velocimetry) method, the change of Strouhal number with frequency was examined, and time averaged flow structures and vortex sheddings were presented. In another study including a single bluff body, Şahin, Akkoca, Öztürk, and Akilli (2006) investigated the horseshoe vortex system and formation around a vertical cylinder. The stagnation points moving forward and back along the flow axis and showing the horseshoe vortex event were determined. Zhang and Perot used a different model in the prediction of the flow characteristics around a triangular cylinder. The effect of the vortex generators parallel to the cylinder placed into the channel on the flow field was investigated by (Akansu, 2004). It was concluded that the vortex generators placed into the flow field had an important effect on the track region around the cylinder and the flow field in the boundary layer.

As understood from the studies available in the literature, direct or indirect interventions to the flow, and the flow around the immersed bodies, cause changes in the flow formations. An experiment to determine how the flow parameters around a bluff body surface from which the suction and blowing were made was numerically conducted by Menter (1994). Zhang, He, and Tao (2009) experimentally investigated the flow formation of a cylinder left behind the wing. It was concluded that the cylinder was completely under the effect of the wing profile when it was at the top. The flow blockages, or obstacles, left in the fluid flow cause more complex flow formations, regular or irregular vortex sheddings, the flow blockages. The aerodynamic forces and the changes of the Strouhal number with the Reynolds number and gap ratio were studied by Wang (1996). It was observed that the increase of the Reynolds number value up to 500 increased the Strouhal number, after this value the Strouhal number did not change. It was also concluded that the fluctuation forces affecting to the upstream cylinder were higher than those of the downstream cylinder. Two and three dimensional experimental studies of the sharp edged blockages were made by Ozgoren (2006). At the end of the analyses, they defined four different regimes. The previous researcher 
examined the turbulent flow around two bodies mounted onto the surface and reported that different flow formations occurred depending on the gap ratio between the bodies. 3D numerical flow analysis for two cylinders with equal diameters placed in tandem was conducted by Ozgoren (2006).

In literature survey, it can be clearly seen that no study involves the edge length effect of equilateral triangular bodies on flow structure, thus no study giving detailed analysis of the flow field there exists. Many studies only give details for the back track region of bodies. Flow around equilateral triangular bodies (both before the bodies, on bodies and after the bodies) has been first examined in detail. In this study, the flow structure around two identical triangles placed side by side has been investigated experimentally. The goal of this experimental study was to investigate the effects of the edge length of the bluff bodies on flow structure. The flow characteristics are performed for a Reynolds number range varying from 5000 to 10000 under steady state conditions.

\section{EXPERIMENTAL SET-UP}

The experimental facility used in the experiments is schematically shown in Figure 1. The facility includes a laser and its equipment, a computer, two water tanks, a pump, rectangular fiber glass channel with triangular bodies replaced as single and a circulation pipe. The thickness of the fiber glass channel is $10 \mathrm{~mm}$. The inner and outer faces of the water tanks are painted against corrosion, and the outer faces of the triangles are also painted black so as not to reflect the green light. The side length of the triangles is $1.5 \mathrm{~mm}, 2 \mathrm{~mm}$ and $2.5 \mathrm{~mm}$, and they were placed tightly so they don't move due to the pressure effect of the flowing water. The details of the triangular bodies are presented in Figure 2. The water tanks and the fiber glass channel were filled with water. In order to unload the water inside the tanks and the channels, emptying valves under the tanks were used. Confiner pollen seeds with $40 \mu \mathrm{m}$ diameter are used for water flow. As seen from Figure 2, the inner height of the channel $(\mathrm{H})$ is $150 \mathrm{~mm}$, and, the inner width (W) of the channel was $100 \mathrm{~mm}$.

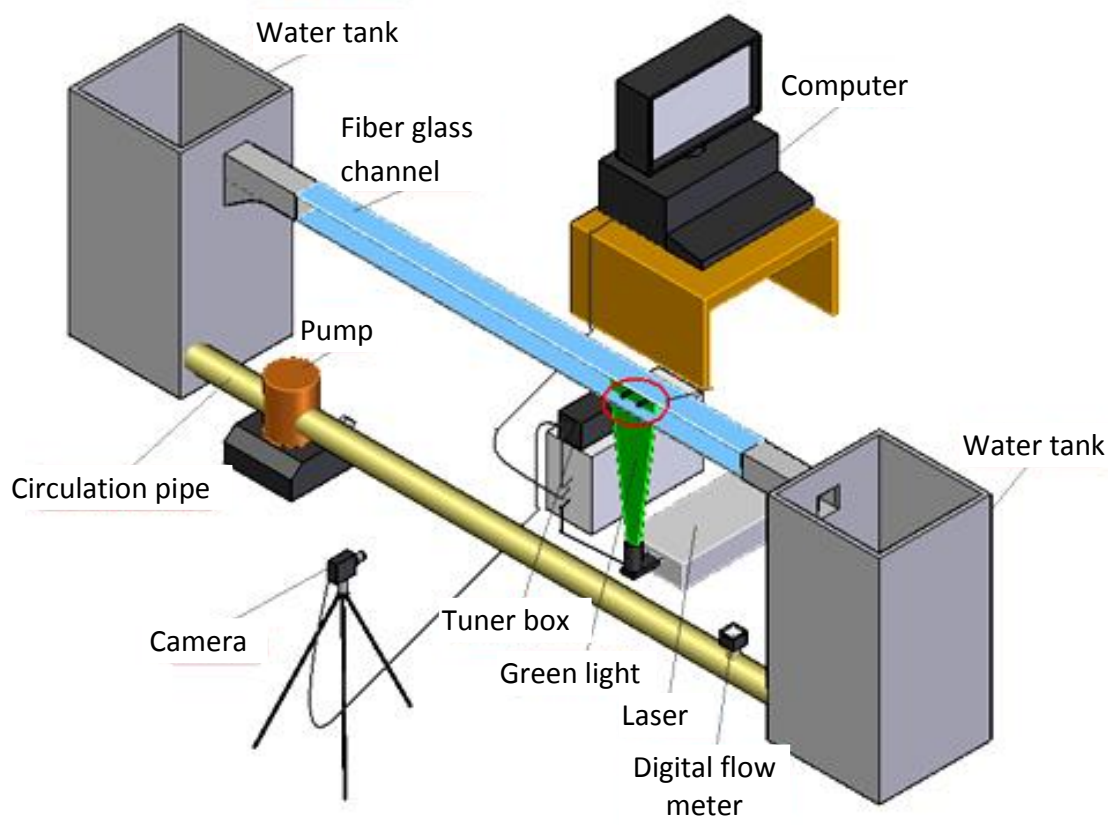

Figure 1. Experimental set-up of particle image velocimetry (PIV) system. 
The inlet water, whose temperature is $300 \mathrm{~K}$, is first driven by the pump, so that the water moves along the channel. While the water is moving inside the channel, water passes the blockages placed into the channel in tandem. Finally, water enters the other tank, and, this circulation continues during the experiments. Once the flow reaches steady state, the laser is turned on. Before turning on the laser, the steps listed below are followed.

- The camera is opened while shutter is closed.

- The sharpness of the seeds shown by green light is set by snapshot.

- The system is calibrated by defining the measure scaling factor.

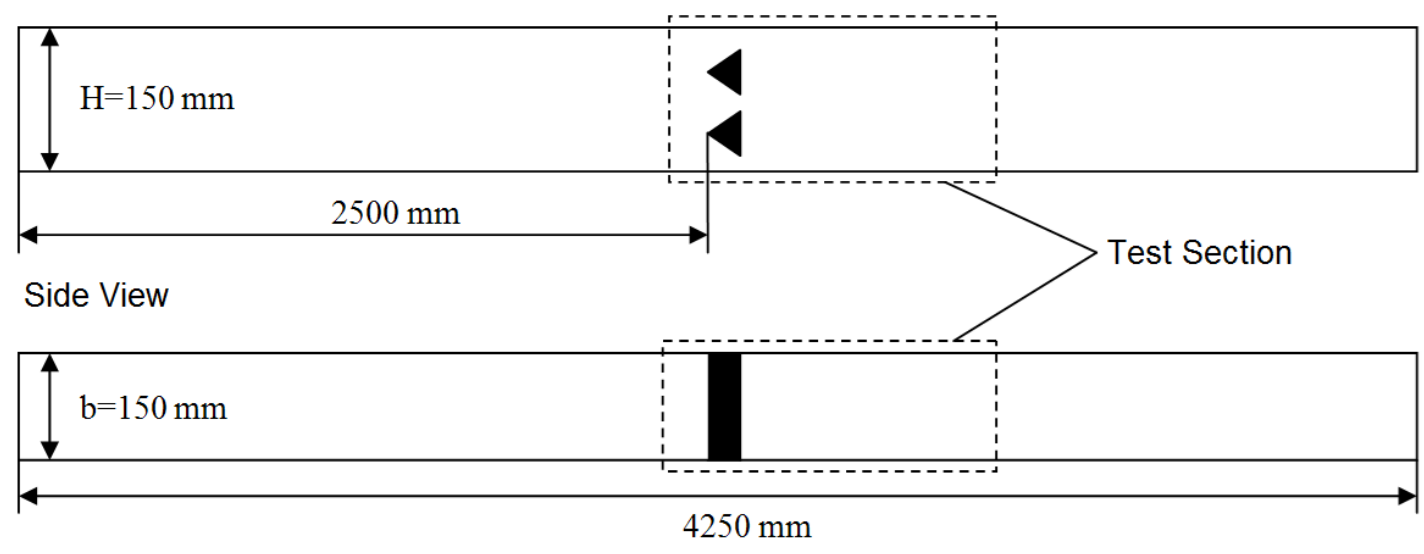

Top View

(a)

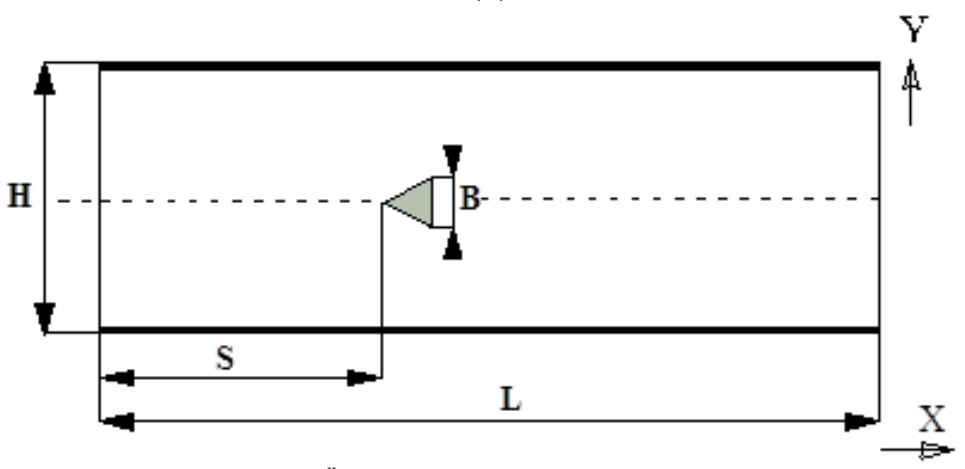

(b)

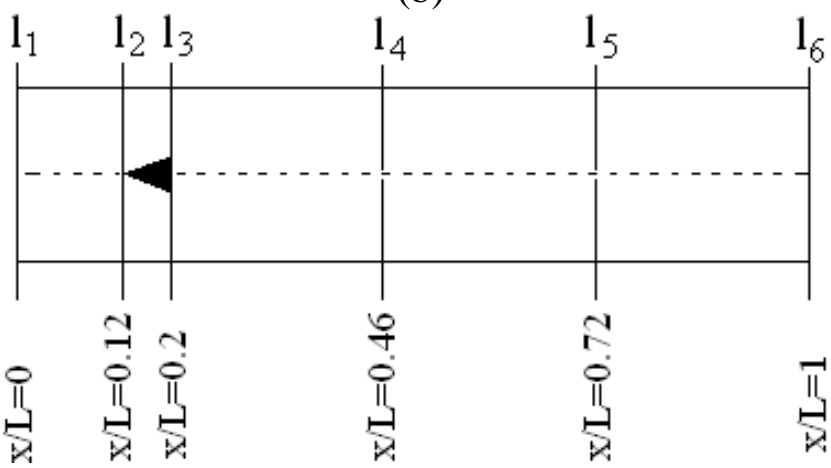

(c)

Figure 2. a) The side and top view of the channel, b) the schematic view of the test section, (c) velocity distribution lines. 
The laser is then turned on. The images are taken of the experiments, and these images are processed to obtain the required prints for analysis. The volumetric water flow rates controlled by digital flow meter from the pump are adjusted by varying the motor speed through an inverter. The data, except for that of the volumetric flow rate, was recorded by a computer connected with a laser. The various characteristics of the flow were calculated using the DANTEC v2.30 computer software.

\section{RESULTS AND DISCUSSION}

The velocity distributions of six different lines $\left(1_{1}, 1_{2}, 1_{3}, 1_{4}, 1_{5}, l_{6}\right)$ are presented in Figure 3 . The velocity profiles were examined on six different points along the channel in order to get better idea about how the velocity profile changes on first facing the bodies, after passing the bodies and at the end of the channel. The lines showing six different $\mathrm{x} / \mathrm{L}$ distances are presented in Figure $2 \mathrm{c}$ as described. In Figure 3, the first line belongs to $\operatorname{Re}=5000$, the second line belongs to $\operatorname{Re}=7500$ and the last line belongs to $\mathrm{Re}=10000$. As understood from the velocity distributions on Line 1 , the fluid has a fully developed velocity profile at the channel inlet.
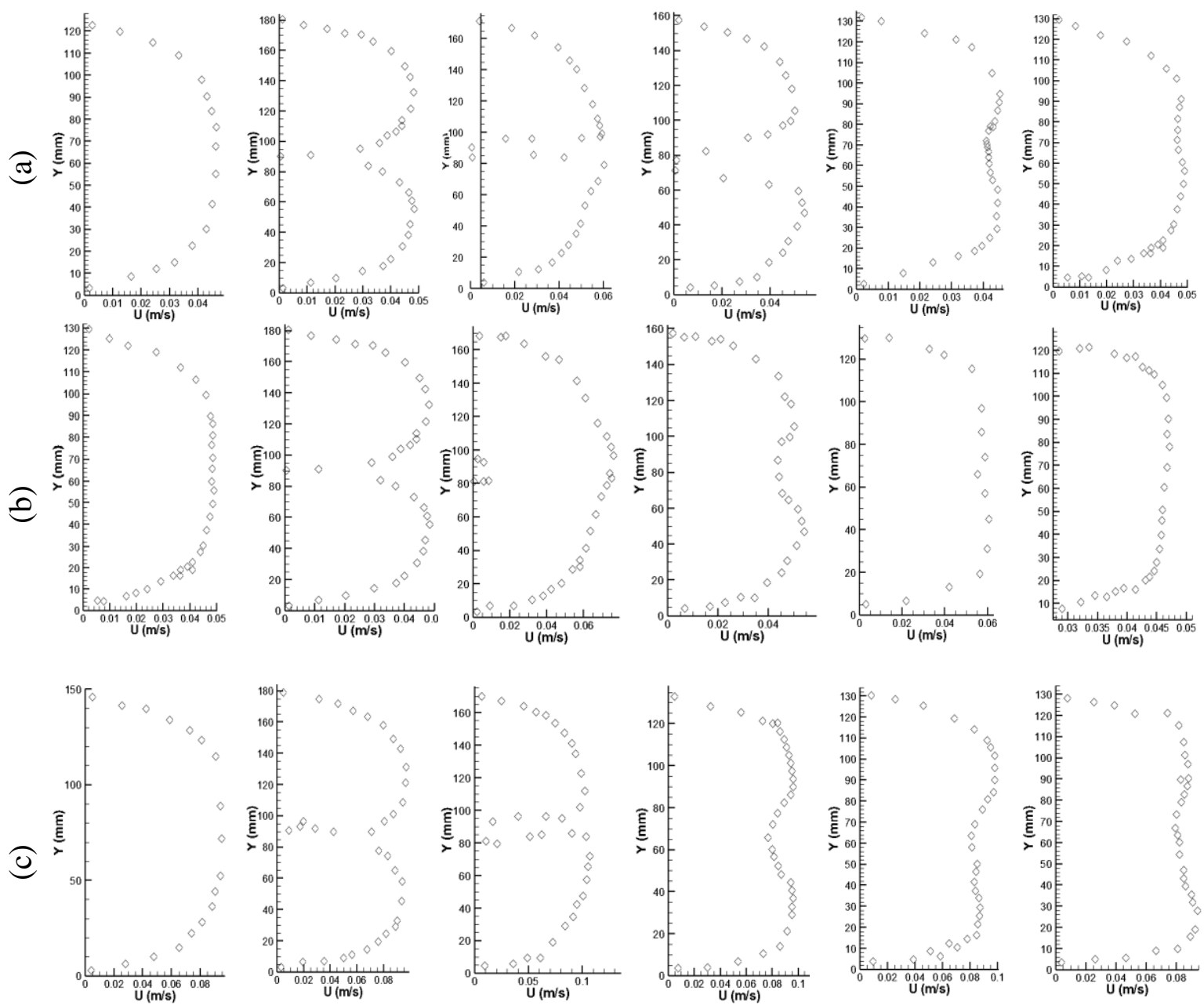

Figure 3. Velocity profiles from the channel inlet to channel outlet $\left(1_{1}, 1_{2}, 1_{3}, 1_{4}, 1_{5}\right.$ and $\left.1_{6}\right)$ for $\mathrm{B}=1.5 \mathrm{~mm}$ at (a) $\mathrm{Re}=5000$, (b) $\mathrm{Re}=7500$ and (c) $\mathrm{Re}=10000$.

The uniform velocity profile at the channel inlet changes depending on the types of arrangement of the bodies in the channel on the first facing time and the position. At 
the point at which the fluid makes the first contact with the tips of the bodies, the velocity becomes zero. At the tips of the obstacles, the flow field is divided into two zones. In these two zones, the velocity profile is saved. Exactly, a part as the height of the triangles $\left(l_{3}\right)$ becomes zero on the velocity profiles. After the fluid passes through the bluff bodies, upon moving towards the end of the channel, the velocity which is zero on the axis begins taking positive values. Towards the end of the channel, this value gets higher and higher. The fluid profile nearly reaches the profile at the channel inlet. As understood from the velocity profile variations along $\mathrm{x}$-distance, the most effective parameters are the flow velocity and the back track region.

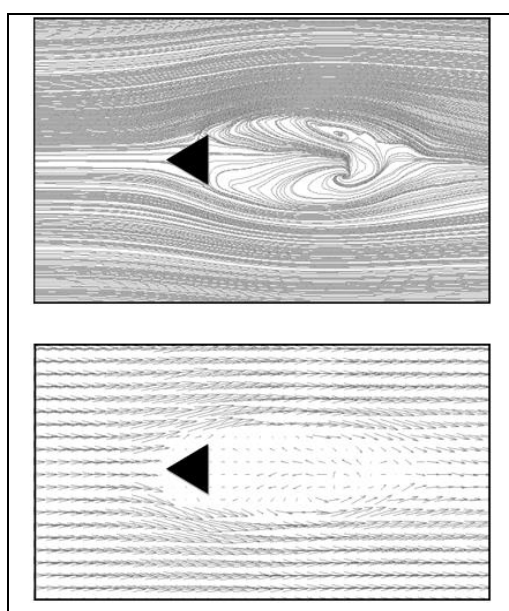

(a)

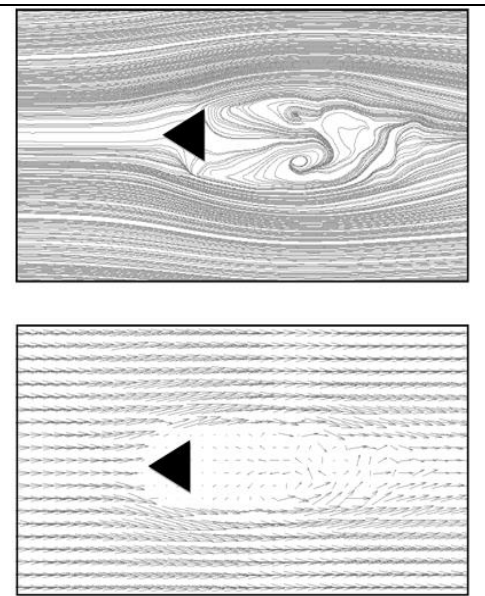

(b)

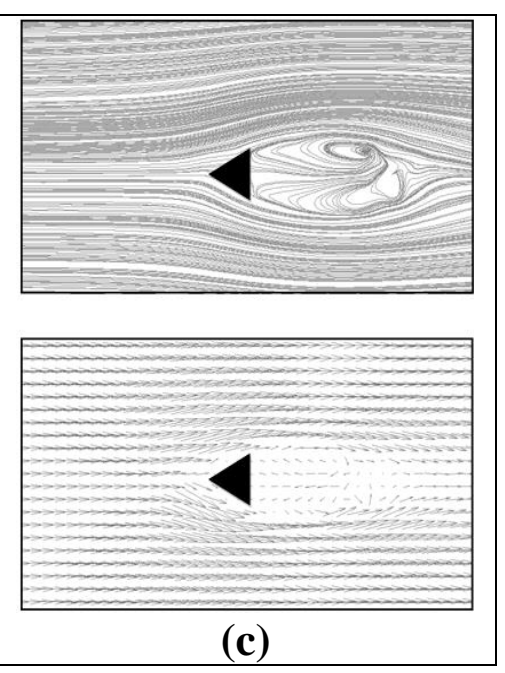

(c)

Figure 4. Stream lines (on the top) and velocity vectors (below) at (a) $\mathrm{Re}=5000$, (b)

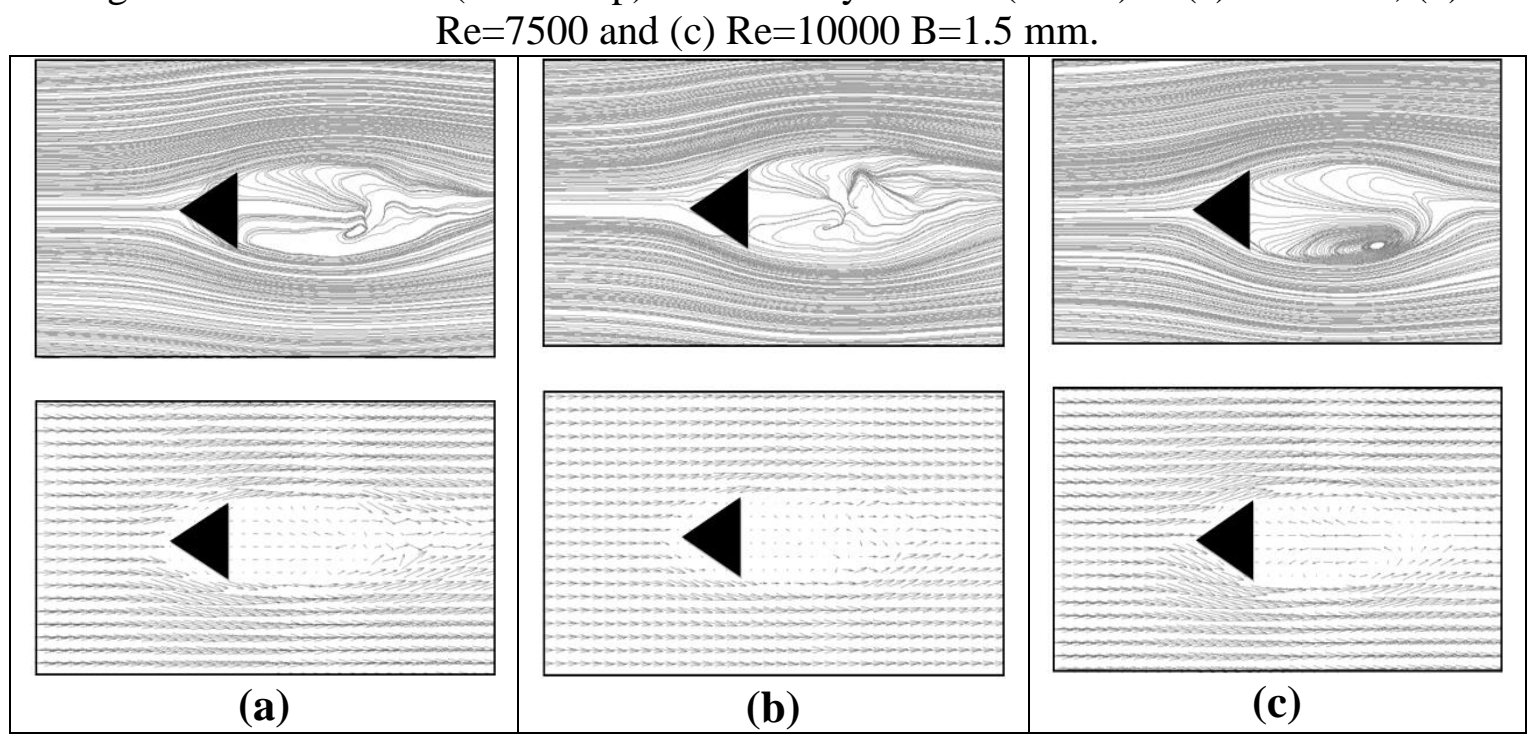

Figure 5. Stream lines (on the top) and velocity vectors (below) at (a) $\mathrm{Re}=5000$, (b)

$\mathrm{Re}=7500$ and (c) $\mathrm{Re}=10000 \mathrm{~B}=1.5 \mathrm{~mm}$.

The velocity is zero at the Line $2\left(l_{2}\right)$,-stagnation point. After this point the fluid changes its direction depending on the geometry of the obstacle which the fluid encounters, and continues in its motion. On Line $3\left(l_{3}\right)$ - exactly at the back of the triangles - in a region known as the back height of the triangle because the value of the velocity vectors at the back of the bodies is zero. In the upstream and the downstream regions of the same line, the value of the velocity is bigger than the inlet value. This is because the fluid passes from a more narrow section. In Line $4\left(1_{4}\right)$, the value of the 
velocity increases and begins taking positive values. The velocity profile at the channel exit is nearly equal to that of the inlet section.

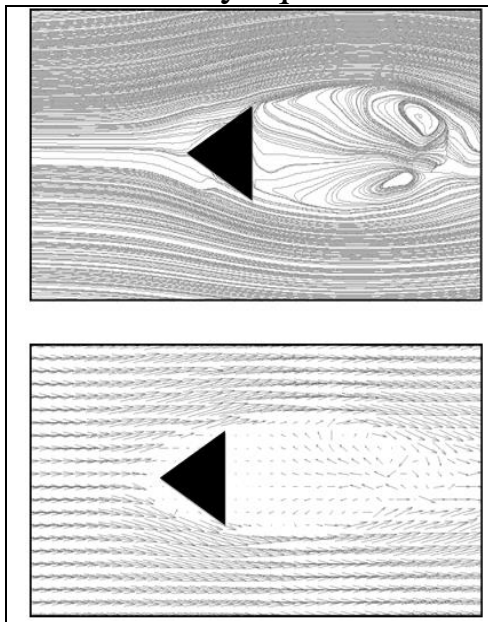

(a)

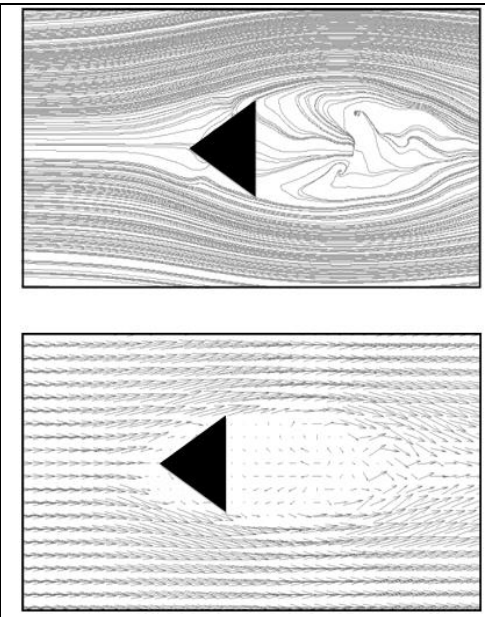

(b)

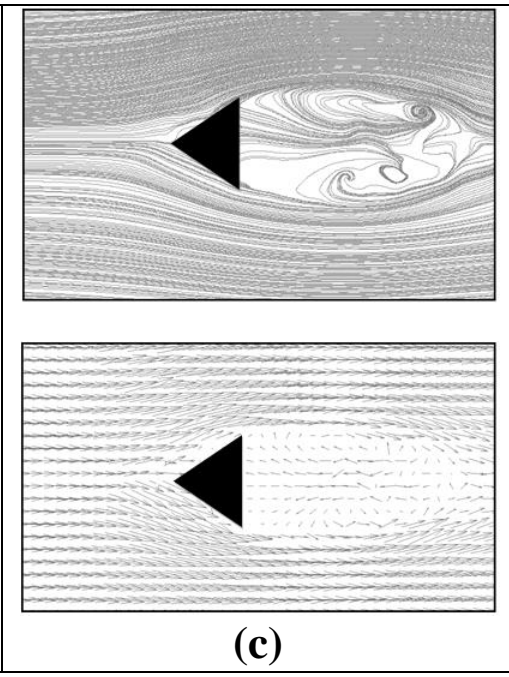

(c)

Figure 6. Stream lines (on the top) and velocity vectors (below) at (a) $\mathrm{Re}=5000$, (b) $\mathrm{Re}=7500$ and (c) $\mathrm{Re}=10000 \mathrm{~B}=1.5 \mathrm{~mm}$.

In Figures 4-6, the time averaged velocity vectors and the streamlines are shown for all cases investigated. In front of the triangles, the streamlines are parallel to each other. Due to the separations in the upstream and downstream regions, vortex fields occur at the back of the bodies. The size of the vortex fields depend on the size of the track region and the flow velocity. In order to better understand the relationship of the vortex sheddings with the track region width and the Reynolds number, the velocity vectors and the streamlines are presented side by side. On examining the figures, for the upstream and downstream flows, it is seen that the vortices are created after a specific distance as a result of fluid separation from the surface. In other words, the vortices come one within the other due to the fact that the each vector group separating at a specific distance creates their own vortices.

The smallest vortices created by the innermost vector group becomes the center of the integrity created by the same vector group. In fact, this occurring integrity is the creation of the vortex shedding. Two symmetrical vortex fields occur, according to the channel axis, while the sizes of the triangles increase. For $B=15 \mathrm{~mm}$ and $20 \mathrm{~mm}$, an important situation appears due to the small back track region: two separate vortex fields, one small and the other big, occur as a result of the mixing of the flows separating from the upstream and the downstream regions. Another situation requiring attention is the effect of the Reynolds number on the vortex creation length. At higher Reynolds numbers, the flow separations occur on the further points of the back track regions. As mentioned before, these separations cause the vortex creation length to increase and decrease by the decreasing Reynolds number. In Figure 7, the Strouhal number variations obtained by the use of the vortex shedding frequencies with Reynolds number are given. When the graphs are examined carefully, the Strouhal numbers belonging to the triangular bluff bodies replaced into the flow field are seen to be nearly constant. This is because the vortex fields are symmetrical behind the smooth and the symmetrical elements. 


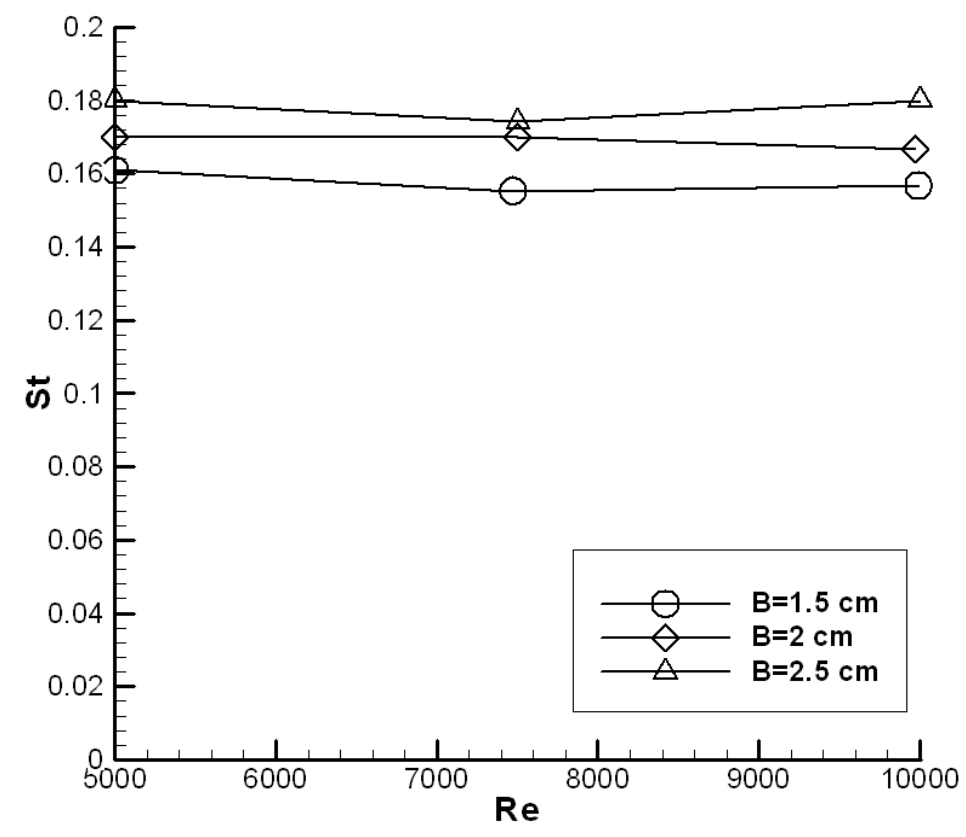

Figure 7. Strouhal number variations versus Reynolds number.

\section{CONCLUSIONS}

Equilateral triangular prisms were installed as single in a horizontal channel. The aim of this study was to investigate the effect of each configuration separately created by equilateral triangular cylinders on flow characteristics. Under steady state conditions, the effects of the edge length on flow characteristics and vortex shedding properties were studied. As a result of the experiments conducted, some significant results can be reported. The most effective parameters of the velocity profile changes were the flow velocity and the back track region. Due to the separations of the upstream and the downstream regions, the vortex fields occurred at the back of the bodies. The size of the vortex fields depended on the size of the track region and the flow velocity. The vortices came one within the other due to the fact that the each vector group separating on a specific distance created their own vortices. Two separate vortex fields, one of which was small and the other large, occurred due to the mixing of the flows separating the upstream and downstream regions. The Reynolds number was affected in the vortex creation length. At higher Reynolds numbers, flow separations occurred on the further points of the back track regions.

\section{ACKNOWLEDGMENTS}

The authors would like to thank the Scientific and Technological Research Council of Turkey (TUBITAK) for financial support under the contract 107M508.

\section{REFERENCES}

Akansu, Y. E. A. (2004). Rdışık olarak yerleştirilen farklı geometrilere sahip küt cisimlerin aerodinamik karakteristiklerinin İncelenmesi. Doktora Tezi. Karadeniz Teknik Üniversitesi, Trabzon. 
Chiu, Y. W., \& Jang, J. Y. (2009). 3d numerical and experimental analysis for thermalhydraulic characteristics of air flow inside a circular tube with different tube inserts. Applied Thermal Engineering, 29(2), 250-258. .

Choi, J. M., Kim, Y., Lee, M., \& Kim, Y. (2010). Air side heat transfer coefficients of discrete plate finned-tube heat exchangers with large fin pitch. Applied Thermal Engineering, 30(2), 174-180.

Ishak, M., Tahseen, T. A., \& Rahman, M. M. (2013). Experimental investigation on heat transfer and pressure drop characteristics of air flow over a staggered flat tube bank in crossflow. International Journal of Automotive and Mechanical Engineering, 7, 900-911.

Jha, S. K., \& Sharma, A. (2013). Optimal automobile muffler vibration and noise analysis. International Journal of Automotive and Mechanical Engineering, 7, 864-881.

Lee, J.-Y. (2013). Sound and vibration signal analysis using improved short-time fourier representation. International Journal of Automotive and Mechanical Engineering, 7, 811-819.

Menter, F. R. (1994). Two-equation eddy-viscosity turbulence models for engineering applications. AIAA Journal, 32(8), 1598-1605.

Nuawi, M. Z., Ismail, A. R., Nor, M. J. M., \& Rahman, M. M. (2011). Comparative study of whole-body vibration exposure between train and car passengers: A case study in malaysia. International Journal of Automotive and Mechanical Engineering, 4, 490-503.

Ozgoren, M. (2006). Flow structure in the downstream of square and circular cylinders flow. Measurement and Instrumentation, 17, 225-235.

Şahin, B., Akkoca, A., Öztürk, N., \& Akilli, H. (2006). Investigations of flow characteristics in a plate fin and tube heat exchanger model composed of single cylinder. International Journal of Heat and Fluid Flow, 27(3), 522-530.

Satya Narayana, P. V., Ramireddy, G., \& Venkataramana, S. (2011). Hall current effects on free-convection mhd flow past a porous plate. International Journal of Automotive and Mechanical Engineering, 3, 350-363.

Tahseen, T. A., Ishak, M., \& Rahman, M. M. (2012). Analysis of laminar forced convection of air for crossflow over two staggered flat tubes. International Journal of Automotive and Mechanical Engineering, 6, 755-767.

Vijaya Lakshmi, B., Subrahmanyam, T., Dharma Rao, V., \& Sharma, K. V. (2011). Turbulent film condensation of pure vapors flowing normal to a horizontal condenser tube - constant heat flux at the tube wall. International Journal of Automotive and Mechanical Engineering, 4, 455-470.

Wang, C.C., Chang, Y.J., Hsieh, Y.C., \& Lin, Y.T. (1996). Sensible heat and friction characteristics of plate fin-and-tube heat exchangers having plane fins. International Journal of Refrigeration, 19(4), 223-230.

Yuan, Z. (2000). Numerical study of periodically turbulent flow and heat transfer in a channel with transverse fin arrays. International Journal of Numerical Methods for Heat \& Fluid Flow, 10(8), 842-861.

Zhang, J. F., He, Y. L., \& Tao, W. Q. (2009). 3d numerical simulation on shell-and-tube heat exchangers with middle-overlapped helical baffles and continuous bafflespart i: Numerical model and results of whole heat exchanger with middleoverlapped helical baffles. International Journal of Heat and Mass Transfer, 52(23), 5371-5380. 